\title{
Social Relations, Long-Term Care, and Well-Being of Older Migrants in Luxembourg
}

\author{
Anne Carolina Ramos and Ute Karl \\ Integrative Research Unit on Social and Individual Development (INSIDE), University of Luxembourg, Esch-sur-Alzette, Luxembourg
}

\begin{abstract}
This paper is based on biographical and qualitative egocentric network analyses and examines the social relations of older Italian and Portuguese migrants in need of long-term care (LTC) in Luxembourg. It addresses three components of their everyday social relationships, including the relationships with emotionally close individuals in their egocentric networks, with careworkers, and with other care-recipients in institutional settings. The findings support two main theses: First, careworkers are central figures in providing emotional support to older migrants; second, the relations with other care-recipients can be difficult to establish in contexts of migration, which leads to the necessity of arranging new forms of institutional settings in order to decrease social isolation, being a pressing aspect to public health policies.
\end{abstract}

Keywords: social relations, older migrants, long-term care, well-being, Luxembourg

Social relations have been acknowledged as a key element of well-being, having a significant impact on health over the life course (Antonucci, Ajrouch, \& Birditt, 2013; Hubbard, Tester, \& Downs, 2003). Studies have emphasized the importance of social relations for self-esteem (Fuller-Iglesias, Webster, \& Antonucci, 2013) and self-rated health (Antonucci, Birditt, \& Webster, 2010), showing that social relations act as a protective resource against cardiovascular disease, cancer, depression, and dementia (Antonucci \& Akiyama, 2002). Among older adults, social relations also influence mortality: People who are more socially integrated live longer (Uchino, 2009) and are less susceptible to infection and illness than their less-integrated counterparts (Brissette, Cohen, \& Seeman, 2002).

In old age, social relations are generally associated with smaller, less frequented, and less proximal networks, with a higher proportion of kin (Ajrouch, Antonucci, \& Janevic, 2001). If, on the one hand, narrow networks are connected to the loss and death of same-age peers or to the individuals' active emotional selection of their satisfactory relationships (Fredrickson \& Cartensen, 1990), on the other hand, this "draining" may also be a consequence of other situational factors, such as chronic diseases and reduced mobility. Physical illness and functional impairment can contribute to social isolation and the need for support, thus affecting older adults' social relations and well-being (Van Tilburg \& Van Groenou, 2002). Moreover, research has shown that older people tend to experience a lack of peer interaction within institutional care settings, spending most of their time in social and emotional isolation (Hubbard et al., 2003). These aspects may be even more relevant among older dependent migrants ${ }^{1}$, due to linguistic barriers in communicating, different ways of interacting and caring, and the impact of migration in their life course (Radermacher, Feldman, \& Browning, 2008; Van Holten \& Soom Ammann, 2016).

The present article sheds light on this situation by analyzing the social relations of older, first-generation Italian and Portuguese migrants in need of long-term care (LTC) in the Grand Duchy of Luxembourg. Specifically, attention is focused on three aspects of their everyday social relationships: their relations (1) with emotionally close individuals in their egocentric networks, (2) with careworkers (encompassing the professional caregivers and other staff), and (3) with other care-recipients in institutional settings. Italians and Portuguese are particularly relevant in the Grand Duchy, where migrants make up 21.4\% of the population aged 65 and over. Italians comprise the largest and oldest group of migrants, though the Portuguese migrant group is growing the most rapidly, increasing 208.9\% between 2001 and 2011 (Zahlen, 2016, p. 43, based on data from 2011).

\footnotetext{
The specific terminology used in this paper is as follows: The term migrants is used for populations who migrated themselves, and the terms ethnicity or ethnic background are used to refer to a person's belonging, which can be collective and individual, (re-)produced in social interaction, and internalized as personal identification, and is always a situational accomplishment (see Torres, 2015, p. 936, referring to Jenkins, 1997). We refer to culture as systems and ways of symbolizing and bestowing meaning which construct differences and boundaries. The term diversity is used to point to differences that correspond with intersecting dimensions of social inequality such as sex, ethnic background, socioeconomic background, impairment, etc.
} 
Although the aging of different groups of (trans-)migrants has received progressively more attention in the last decades, research on this topic is still relegated to the periphery of migration and aging studies (Torres \& Karl, 2016), addressing insufficiently the challenges faced by frail older migrants in need of LTC (Runci, Eppingstall, Van der Ploeg, \& O’Conner, 2014). As Van Holten and Soom Ammann (2016) highlight, "care services are challenged by providing for an increasingly heterogeneous population with respect to socioeconomic background, lifestyles, religious beliefs, supportive networks, and migration" (p. 200). This diversity also leads to the questions of how older migrants interact with others in institutional care settings and how care-providers meet older migrants' needs with respect to their social relationships.

First, we sketch the main aspects of the LTC services in Luxembourg. Using the terminology of LTC services, we include mobile-care services, day-care centers, and residential care homes, as these are the services that provide formal care in the Grand Duchy. Next, we explain the data and the methods used in the study and then analyze older people's social relationships in situations of LTC, with special attention being paid to the different kinds of interaction they have in their daily routines. Our study supports two main theses: First, careworkers are the central figures in providing emotional support to older migrants in need of LTC, especially in home-care services. Second, the relations with other care-recipients can be difficult to establish in contexts of migration, which leads to the necessity of setting up new forms of institutional settings in order to decrease social and emotional isolation. We conclude our article with suggestions and implications for both future research and public health policies.

\section{Long-Term Care Services in Luxembourg}

Compared to other EU countries, Luxembourg has a broad and generous welfare system, with an important social-service sector for older people (Hartmann-Hirsch, 2011). Since 1999, the Luxembourgish care insurance is part of the social security system, widely covering the costs of LTC. The funding is based on the principle of solidarity: Eligibility reflects the needs of the person, with no conditions put on income and no waiting period. The vast majority of the institutional services are publicly managed or run by nonprofit organizations (Ferring \& Weber, 2005).

In order to benefit from the services of the LTC insurance, the dependent person must need a minimum of 3.5 hours per week of assistance in the activities of daily living (with a limit of 24.5 hours per week, which can be increased to 38.5 hours under special circumstances) for at least 6 months, and the need has to be a consequence of a disease or a physical or mental handicap (Ministry of Social Security, 2015). The dependent persons are entitled to two types of services: benefits in kind and benefits in cash.

Benefits in kind are provided by means of professional mobile-care services, daycare centers, and care homes: (1) The mobile-care services are organized by a network of professional caregivers who provide assistance to the home-based dependent person. (2) The daycare centers are places where older people can go during the day and participate in activities while receiving the care they need. (3) The care homes are institutions that accommodate the dependent person continuously, providing assistance during the day and the night.

Benefits in cash cover the costs of informal carers, who are mainly family members or friends (Ferring \& Weber, 2005). However, for reasons of quality, informal caregivers are paid only up to a maximum of 10.5 hours per week. Any remaining hours must be supplied by professional caregivers (Ministry of Social Security, 2015).

The assistance provided by the LTC insurance includes help with personal hygiene, food, mobility, and household tasks as well as with technical assistance and home modification. The policy adopted by the Luxembourgish government can be understood as an "aging-at-home approach" (Ferring \& Weber, 2005 , p. 24), encouraging measures that allow older people to remain independent and at home as long as possible, with the result that most of the beneficiaries $(68 \%)$ reside in their own domicile while receiving care assistance (General Inspection of Social Security [IGSS], 2014).

\section{Data and Methods}

This article is based on interviews with eight older Portuguese and Italian migrants who utilize LTC services in Luxembourg. They were recruited in daycare centers, care homes, and via mobile-care services, and were interviewed as part of the research project "Biographies and Transnational Social Support Networks of Older Migrants in Luxembourg” (BiSoNetMig), financed by the University of Luxembourg $(2013-2016)^{2}$. Specifically, we contacted the administrative staff of the three types of care services to recruit older migrants with no mental disorders and from different backgrounds, varying in age, sex, marital status, geographical localization of the children, and the type of care service utilized. Most of our interviewees are women (6 of 8 ) who had worked in low-skilled jobs and had few years of schooling. In Luxembourg, $79.9 \%$ of the Portuguese and $74.5 \%$ of the Italians aged 65 and over have only primary or lower secondary

2 Ethics approval was given by the Ethics Review Panel of the University of Luxembourg (ERP 13-005). 
Table 1. Sample

\begin{tabular}{|c|c|c|c|c|c|}
\hline Person & Sex & Nationality & Age group & LTC service used & Housing situation \\
\hline Amália & $F$ & Italian & $70-79$ & Mobile care service & Alone \\
\hline Benjamin & M & Portuguese & $70-79$ & Daycare center & With his wife and a daughter \\
\hline Cândida & F & Portuguese & $80-89$ & Care home & Alone, in a care home \\
\hline Conceição & F & Portuguese & $90+$ & Daycare center & With a daughter \\
\hline Gioconda & $\mathrm{F}$ & Italian & $70-79$ & Mobile care service & Alone \\
\hline Mrs. Maldini & $F$ & Italian & $70-79$ & Daycare center & With a daughter \\
\hline Mrs. Rossi & $\mathrm{F}$ & Italian & $90+$ & Care home & Alone, in a care home \\
\hline Mr. Sartori & $\mathrm{M}$ & Italian & $80-89$ & Mobile care service & With his wife \\
\hline
\end{tabular}

education, thereby occupying the lower levels of the social structure (Zahlen, 2016). With respect to age at the time of the interviews, four participants are in their 70s, two are in their 80s, and two are in their 90s. Moreover, the sample includes five Italians and three Portuguese, which is reflective of the age structure of these populations: only $4 \%$ of the Portuguese, but nearly $22 \%$ of the Italians living in Luxembourg are aged 65+ years (Zahlen, 2016). Table 1 reports the main characteristics of our sample ${ }^{3}$.

The older Portuguese and Italian migrants were interviewed by means of biographical and qualitative egocentric network interviews (as developed by Hollstein, 2002), conducted in their mother tongue, on two different occasions. The biographical interview explored each participant's history of migration, their life situation after becoming dependent on care, and their experience with the LTC services. The network interview was composed by a set of three concentric circles in which the names of emotionally close significant others were recorded following a hierarchical level of closeness: emotionally very close, close, and less close (Kahn \& Antonucci, 1980). It was followed by detailed questions about social support, reciprocity, and interactions. The combination of both these methods allows us to determine how the relations have developed over time, the impact of life events on the network, and who the older migrants rely on when in need of support.

Data were transcribed into the participants' mother tongue and analyzed following the grounded theory methodology (Charmaz, 2006). Based on a close reading and coding of our data, we observed that social relations represent an important aspect of older dependent migrants' well-being, and that three main dimensions were important in their daily social interactions: the relations (1) within the emotional egocentric networks, (2) with professional caregivers and other staff, and (3) with other care-recipients in cases of living in a care home or attending a daycare center. In the following, we discuss these three aspects, focusing on the meaning, quality, and functions of these social relationships.

\section{Social Relations Within the Emotional Egocentric Networks}

Studies have found that older people tend to have a more familyfocused network, centered in their emotionally close relationships (Ajrouch et al., 2001). In our data, the spouse, children, grandchildren, and remaining siblings indeed occupy the inner circle, constituting the individuals who are the closest emotionally to our participants. Friends and other close relatives are in the second circle, while the third circle remained empty in all eight network maps. This choice may actually reveal an emotional selection effect (Fredrickson \& Cartensen, 1990), in the sense that they prefer to have the third circle empty rather than filling it with peripheral relationships. Moreover, the first circle has the most entries, which means that the size of the network depends greatly on the number of offspring one has, since the range of contact with same-age peers tends to decline over time. An exemplary presentation of these aspects in the form of a network map is provided for Gioconda, one of our interviewees, in Figure 1.

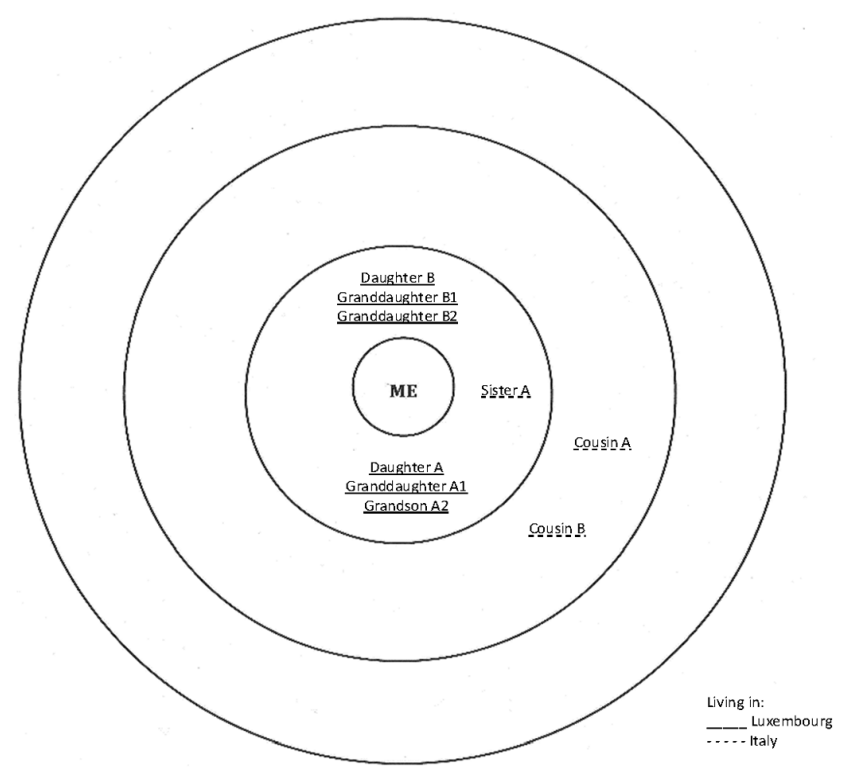

Figure 1. Example of a network map - Giaconda.

\footnotetext{
3 The pseudonym used is generally a participant's first name. However, in some cases, surnames are used preceded by the title Mr. or Mrs. This was done according to the way it was practiced in the interview.
} 
While the children are mostly located in Luxembourg, friends, siblings, and other close relatives live predominantly in the home country, which represents an important feature in the lives of older dependent migrants. Although emotional bonds are maintained despite geographic distance and less personal frequent contact, advanced age and reduced mobility limit them to cultivating solely virtual relationships. Same-age peers are very significant for the well-being of older adults because they represent an important source of emotional support that children rarely can provide. "I don't have confidence in anyone else," says Gioconda about the intimate relationship she has with one of her Italian cousins.

Gioconda: We talk about everything, I went to her, she cries because she fell, she tells me about her problems with her children, the misery in Italy. To sum up, we talk about everything .... I give to her and she gives to me. (Network Interview)

However, it is not always easy to maintain long-distance relationships. Cândida, who lives in a care home subsidized by the National Solidarity Fund and receives some pocket money from her daughter, highlights the difficulty she faces to pay the telephone bills: "By phone I cannot talk much, it's expensive," she explains. Thus, she and her Portuguese friends have to talk briefly every 2 months only "to say hello and to ask how you are and how is your health.” The lack of infrastructure, resources, and cultural capital may clearly lead people to be less able to access new information and communication technology (ICT) than others (Wilding, 2006). Besides her friends, Cândida does not feel that she has someone left in her network who could be a shoulder to lean on in times of difficulty. About her daughter, she says:

Cândida: No, I keep [my feelings] to myself. To whom could I talk, my friend? If I talk to my daughter, she doesn't like me to tell anything: "Look mom, you're in a different age, you're already old ... You shouldn't expect happiness, mom." She makes me feel even sadder! Then, I keep my feelings to myself. (Network Interview)

Cândida's statement shows that children may not be a source of emotional support because they may not understand the age challenges experienced by their aging parents. Moreover, older adults might prefer not to seek the emotional support of their children because they do not want to be a hindrance in their lives or want them to become distressed because of their daily problems, especially when they do not live in the same country, as the case of Amália, whose children are in Italy:

Amália: No. My children, if I'm feeling bad, I never say to them that I'm bad. On the contrary, I make them see that I joke and laugh on the phone. What should I say? They ask me: "Mom, how are you?" The younger understands when I'm lying ... In these cases, he starts joking with me to make me laugh. It's a terrible situation! (Network Interview)

Baldock (2003) also found this attitude in her studies about transnational care among Dutch migrants and their parents left behind in the Netherlands: She reports that "migrants would hide from their parents that they were homesick, physically ill or depressed; parents would not tell their children about their health crises or about deaths in the family" (p. 53). In the case of Amália, who lives alone and has no family member in Luxembourg, the way in which she and her son deal with a difficult situation is to make jokes on the telephone. However, she warns that this type of banter represents a "terrible" way to mask the reality.

The fact that children are not able to or have elected not to provide emotional support does not mean, however, that they are absent in the support networks of older dependent migrants. Actually, most of the instrumental support is provided by professional caregivers in combination with the children, especially in case of widowhood. Mrs. Rossi's sons take care of her medical appointments, Cândida's daughter brings her the clean laundry, while Amália's son sends her packages filled with groceries from Italy. Nevertheless, the intensity of this contact varies widely among our interview partners, depending on their children's life situation, the quality of the parent-child relationship, the geographical proximity, and the way children perceive their family responsibilities in care relations.

Our data show that older dependent migrants do have close and supportive others, but that their social networks are relatively small and geographically dispersed between the home and the host countries. This means that face-to-face contact occurs primarily with children and grandchildren based in Luxembourg, which depends on the availability and the quality of the family ties; and that the location of the same-age peers in the home country represents a challenge to their social interaction and exchange of emotional support. In this sense, the daily contact with professional careworkers and with other dependent people in care facilities, especially to those who live alone, represent an important source of social relations and emotional support, a topic which we discuss next.

\section{Social Relations with Professional Caregivers and Other Staff}

Gioconda: They come in the mornings and they give me a shower... Then, they put the prosthesis on, the socks, the shoes, and give me the walker ... I go to the kitchen, they prepare my coffee and I take my medications ... At noon, they stop by my place for 10 minutes ... They call it coucou passage: 10-15 minutes that they come here to check if I need anything ... On Wednesdays and on Fridays they pick me up to go outside ... from 1:30 pm to 5:30 pm we go to [supermarket A] or to [supermarket B]. They must stay with me for 4 hours! I do the shopping and they help me to read because I don't read in French. They help me: "this [product] has less calories, this isn't good for diabetes.". .. In the evenings, they stop by my place, for another coucou passage. They put on my pajamas, rub the cream on my legs, and help me if I need anything else. They stay with me 5-10 minutes and then go away. (Biographical Interview) 
The narration provided by Gioconda shows in detail the importance of the professional caregivers in her daily life. Gioconda lives alone, and she began receiving mobile-care services almost 20 years ago, after she became severely impaired. At this point she stopped seeing her daughter daily and receiving care from her. Since then, mobile caregivers have been providing care three times a day: shortly after she awakens, at lunchtime, and before she goes to bed at night. Gradually, they have become part of her family: "It's true that I'm the customer, there's always respect, I agree, but between us, after such a long time, we've become a family," she says.

Gioconda has an active social network, receives practical help from her daughter, and emotional support by telephone from her cousin. However, she lacks face-to-face social interaction: She does not go out alone because she cannot walk, and she does not receive any other visitors besides her daughter. When she is asked about who visited her at home during the last few weeks, she replies: "The girls [from the mobile-care service]." To Gioconda, the professional caregivers have become not only part of the family, they are the only people with whom she shares aspects of her daily life.

Gioconda: Me, I talk about my life or my problems, it's normal, I have to talk with someone ... As I cannot talk to my family, I don't have anyone left ... to say ... For me, it makes me feel good. ... For me it makes me feel good to talk ... [That's why I say]: "You are my strength, you are the people to whom I talk about everything!" (Biographical Interview)

As she says, professional caregivers are not only crucial because they provide hands-on care, but also because they give her the daily emotional support that her family can no longer provide: "I cannot talk to my family, I don't have anyone left," she declares. Gioconda emphasizes their centrality in her life by saying that they are her "strength," the people who she can talk to, which she considers central for her well-being: "I have to talk with someone," explains Gioconda about her need for social interaction and support. Amália, who, similar to Gioconda, also lives alone and cannot go outside without assistance, calls the female caregivers "mes filles" [my daughters], again indicating a family relationship. Sometimes she invites them to keep her company during lunch:

Amália: I said: "Stay here to eat with me." Then she said: "I should take a break." I said: "Take your break eating here." She shouldn't accept, but she stayed and we ate together. (Biographical Interview)

In this passage, Amália emphasizes that, although she insisted, she is aware that eating together with clients is something a caregiver should not do. The same happens to Gioconda. Even if she tries to have a close relation with them, this idea is not usually welcomed: “'I want a family relationship,' 'But it's not allowed,' they say.” In their narratives, Gioconda and Amália address the general point of view that part of the professional role of the care-providers is that they should not become too close to their clients to avoid emotional dependency. However, to Gioconda and Amália, both living alone and deprived of other face-to-face social interactions, this daily contact with their caregivers represents an important source of well-being. This feature is interesting because besides possible gender differences, Mr. Sartori, who also receives LTC at home, does not even mention the importance of social interaction with his caregivers, probably because he lives with his wife, sees one of his sons almost every day, and together with the daily professional care, he also receives practical support from his family.

In fact, studies show that "where and with whom a person is living is an important condition with regard to social support and social relationships ... [since] it gives differential opportunities for social contact” (Fernández-Ballesteros, 2002, p. 647). Living alone, combined with the amount of time one spent alone, and low levels of social contact, may lead to feelings of loneliness. Indeed, social and family relationships seem to be crucial aspects in the definition of a "good quality of life" in old age (Victor, Scambler, Bond, \& Bowling, 2000). Moreover, Makoni and Grainger (2002) argue that caregiving should be understood at least in two dimensions: the physical act of caring and helping someone (hands-on care) and the affective state of mind of a person with regard to another, which could be "paraphrased as a 'concern' and sometimes 'love”' (p. 807). They suggest that communication should be perceived as an elemental part of caregiving, and that professional carers should receive training on the relevance of interaction to providing care (Antonucci, Okorodudu, \& Akiyama, 2002). These "communication skills" are even more important in contexts of migration, where care-providers and care-recipients may not speak the same language.

Gioconda (on the mobile-care service): Many times I get upset because they send me girls who only speak German! ... We're not in contact! I speak and that one is mute: "Hum, hum, hum" ... I said: "You, 4 hours with a girl, without saying a word, ... do you understand how this is?" (Biographical Interview)

Cândida (on the care home): There are large meetings here. They invite me, I go there and I tremble from head to toe because I hear them [the directors] speaking [Luxembourgish]. I would like to say something, but in Luxembourgish I cannot. I cannot. They invite me to the meetings and I avoid going because I don't understand what they say! (Biographical Interview)

The experiences of Gioconda and Cândida portray the language complexity in Luxembourg. The first complains about the fact that the caregiver, who should promote social activities, speaks only German. The latter laments that the meetings in her care home are often in Luxembourgish. Both would prefer to use French to better experience the care assistance they are receiving. In a country with three official languages (French, Luxembourgish, and German) and a large number of foreigners, that is, nonLuxembourgish passport holders (according to STATEC, on January 1,2015 , they made up nearly $46 \%$ of the total population), it is not always possible to have caregivers who speak the same language as the care-recipients (as the case of Gioconda) or to 
conduct the institutional meetings in French (as the case of Cândida), since older migrants still represent a minority inside the care homes (Ferring, Heinz, Peltier, \& Thill, 2013).

However, this plurality of languages may also lead to an opposite situation. Because Luxembourg is characterized by the significant migration of careworkers who come mainly from the neighboring countries Germany, France, and Belgium, but also from Portugal, Italy, and other EU countries (Koch \& Weisgerber, 2011), care-recipients also have the opportunity to meet caregivers and other staff (such as institutional drivers, cleaners, attendants, and cooking staff) who speak the same language, come from the same country of origin, or have the same national roots. Because of this heterogeneity of ethnic backgrounds, for example, Gioconda and Cândida also experience the opposite situation than the one just described above: Gioconda has an Italian caregiver whom she considers to be more pleasant than the noncompatriots because of the way he "explains things, how he speaks, [and] the jokes he makes." Cândida, in turn, has a close relationship with a Portuguese staff member who works in the kitchen of the care home where she lives. She has become the only other person she speaks to besides the few contacts she has in her egocentric network. When Cândida is asked about who she talks about her daily life with, she says:

Cândida: I don't leave my bedroom. To do what? To talk to the Luxembourgers? I don't talk with them because they don't permit conversations with us [the Portuguese]. I talk to the [Portuguese worker] on Thursdays, when I go there [in the kitchen] ... In this house, the [Portuguese worker] is the only person I talk to ... And sometimes, I ask her to make tomato rice [a typical dish from Portugal]. They [the Luxembourgers] don't like tomato rice, they think it's sour, it's acidic, they just like sweetmeats. Then, sometimes she makes tomato rice just for me and for her, because she also likes it very much. (Network Interview)

Benjamin, who attends a daycare center, explains the meaning of friendship by taking as an example not a relationship with a close friend, but rather with a former Portuguese assistant at the daycare center he attends. He says:

Benjamin: Friendship is when we get along with a person and we're always ... one trusts another. For me, that's friendship ... As like with a girl who worked here for 2 years. She used to tell me all her secrets and I have them here, inside. Many times people ask me: "What did the [Portuguese woman] say to you?" "Anything!" ((Laughs)) One should keep a secret, secret. For me, you've got to keep things inside, this is what makes a friendship. (Network Interview)

The descriptions of Gioconda, Cândida, and Benjamin show the importance of culture and language in providing care, which includes not only caregivers, but also other staff members involved in their care arrangement. As Stoller and Perzynski (2003) argue, ethnic traditions, eating ethnic foods, sharing memories, and the same ethnic background can foster closer relationships between care-recipients and careworkers, giving an individual the feeling of community or even kinship. It "facilitates the emergence of friendships in which members dis- cover overlapping threads in their personal narratives" (Stoller \& Perzynski, 2003, p. 379). Despite some challenging situations between caregivers and care-recipients, careworkers are highly evaluated by older dependent migrants, indicating that the personnel are mainly interacting effectively with them, an aspect that has also been found in other studies (Runci et al., 2014). In fact, as we are going to analyze next, this proximity can be crucial for coping with the difficulties faced in the social relations with other care-recipients.

\section{Social Relations with Other Care Recipients}

Older dependents who attend daycare centers or live in care homes have the opportunity of interacting with other care-recipients, thus expanding their social relations (see also Hubbard et al., 2003). However, the significance of this interplay is qualitatively different between the two groups. While the former can choose its periodicity, going back home at the end of the day, the latter have experienced a relocation, which also affects their daily life patterns, social networks, and support (Lee, Woo, \& Mackenzie, 2002). Although care institutions accommodate many care-recipients who could potentially become a source of emotional support and positive social interaction, institutionalized social relations may be challenging, especially when involving migrants. Cândida, who is the only Portuguese migrant without dementia living in her care home, faces many difficulties in interacting with Luxembourgers in French, who make up the majority of the inhabitants.

Cândida: What I would do, if I could change something here, is the contact from them to us, and us to them. I'm talking about the residents, not about the personnel, about the residents. To get along with each other! Because for unhappiness, it's enough being here, in this house, right? If we had contact with each other, we would spend more time together and the time would pass by faster, right? The time would pass by faster and we would be happier. (Network Interview)

Cândida highlights that language communication is the only aspect she would change in the care home where she lives, an action that would include the other residents but not the personnel, since the careworkers are generally open to communicate in French. Actually, most of her restrictions inside the care home, such as talking to others and participating in meetings, exist because of the language spoken by her roommates. On the one hand, most Italian and Portuguese migrants have only had a few years of schooling and tended to acquire only French, which is closer to their mother tongue (Dickes \& Berzosa, 2010). On the other hand, although many Luxembourgers speak and understand French, they prefer to speak Luxembourgish, a situation that causes migrants like Cândida to remain apart.

Reviewing Cândida's narrative makes it clear that contact with other care-recipients may not be easily established, although it constitutes an important aspect of her well-being. The 
mutual negative labeling of the "others" (she calls the Luxembourgish inhabitants "racists"), the presence in different locations (the majority group is occupying the lounge, while Cândida stays in her room or goes to the kitchen), and the language as a factor of impairment all play an important role in shaping her social relationships with other care-recipients. Mrs. Rossi experiences a similar situation in which despite actively seeking togetherness, she does not manage to interact with them:

Mrs. Rossi: Yesterday, they were serving coffee in the living room. I went downstairs just to have companionship ... At the table there were three women talking in Luxembourgish. I didn't understand anything ... That's hard. Instead, if I were among Italians, everything would be completely different! (Network Interview)

Although relationships in LTC facilities are typically short-lived, devoid of intimacy, and therefore do not replace the contact with life-long friends or intimate relatives (Bear, 1990), research has shown that everyday social interactions are associated with well-being: "Of all the daily stressors that individuals experience, negative social interactions are the most frequently associated with poor well-being” (Antonucci et al., 2013, p. 89). Thus, extremely important to the social relations of older dependent migrants is not only the quantity, but also the quality of contact with other care-recipients. This should be promoted more systematically within institutional settings.

If we analyze the motivations underlying an individual's choice of care homes and daycare centers, it becomes clear that the social relationship is the main aspect selected by older migrants in our data. Mrs. Maldini says that she decided to spend time at the center because her daughter works all day: "Thus, I prefer to come here because I've got companionship. At home, I'm alone ... It's bad to be alone at home," she declares. Benjamin, who lives with his wife, also decided to attend a center in order to interact with other people: "Because me, at home, I get nervous. And here ... here I've people I can talk to. My wife, at home, she cannot talk with me all the time! She's always busy with housework."

As we can see, "to have companionship," "to have someone to talk to," and "not to be alone" are important aspects in older people's LTC arrangements. If some of them manage to achieve this aim, like Mrs. Maldini, who meets other Italians at the center, with whom she plays cards and talks about her life, others are quite isolated inside the care institutions. This was the case for both Cândida and Mrs. Rossi at a care home, but it is also the case for Conceição, who attends a daycare center. Conceição goes to the center from Monday to Saturday and always has the same routine: "I don't do anything. Here I do nothing. Either I'm sitting here or I'm lying down in bed." Seated alone on the corner, looking at the wall, she repeats from time to time: "There was a clock there; it isn't there anymore, to see the hours ... At 5 o'clock I go back home. There's still too much time left." Since she does not speak Luxembourgish, Conceição only communicates with the careworkers, waiting each day until it is time to return home.

\section{Discussion}

Social relations have been a central topic of interest in gerontological research (Antonucci et al., 2002). However, we still know very little about the ways in which migrants experience social relations in LTC facilities and how social relations are affected not only by age and health, but also by ethnicity. In this study, we shed light on this problem by analyzing three spheres of older dependent migrants' social relationships - specifically, their relations with emotional networks, with careworkers, and with fellow care-recipients.

In agreement with the study of Antonucci et al. (2013) on older people, our data show that older dependent migrants also have narrow, albeit close and supportive, convoys of social relations, centered on offspring and same-age peers, who occupy the first and the second circles of the emotional network, respectively. Children, although placed in the inner circle, do not appear as a main source of emotional support, but rather as an important source of instrumental support, which is combined with professional care. Friends and same-age relatives provide most of the emotional support, however, often from a distance. Because they are mainly located in the home country, face-toface contact is practically nonexistent. Ties are cultivated transnationally by telephone, a fact that can be limited because of the lack of financial resources. In this sense, geographical proximity, combined with health impairment, and socioeconomic constraints, affect their social relations and exchange of emotional support within the network members.

Against this background, the contact with careworkers and other care-recipients in institutional settings becomes an important aspect of their social relationships. In their narratives, older dependent migrants show that it is not only the people within the emotional egocentric networks who provide emotional support: Careworkers, although not included in their network maps, often become a source of comfort and consolation in their daily lives. Furthermore, besides the quality of the relationships with the network members (Antonucci \& Akiyama, 2002), the quality of the contact with professional caregivers and other care-recipients also seems to affect elders' well-being.

Most of the daily contacts in situations of LTC are made with professional caregivers and other care-recipients. Not being at home alone and having regular contact with others is, indeed, an important motivating factor to start using institutional services. In our data, older migrants make it clear that they wish to interact with others in their social contexts. Nonetheless, this social interaction does not necessarily coincide with positive experiences, and here ethnic background and language proficiencies become important.

On the one hand, caregivers and older dependent migrants may not speak the same language, creating some obstacles in care relations, especially when professionals are responsible for promoting social activities. On the other hand, the multicultural background of health workers in Luxembourg creates the 
possibility of having caregivers from the same ethnic background, which makes relations between caregivers and care-recipients even closer, due to their shared language and culture and sometimes even their similar sense of humor and tastes. Our study shows that this proximity also includes other staff members, who may be important to buffer the experienced social isolation, an aspect that should be included in the research agenda on LTC.

A difference is observed, however, in the contact with careworkers in the three contexts of LTC in Luxembourg: Interviewees who receive mobile-care services at home reflect more about the detachment of professional caregivers to prevent emotional dependency. Warm contacts with caregivers are very important to them, especially when living alone, as they become significant others during the course of care provision. In care homes and daycare centers, these contacts are also important. However, older care-recipients in institutional settings can take part in (organized) activities, making friends with other staff members, and being in contact with other residents. Our data show that sharing the same ethnic background might bring care-recipients together, whereas feelings of social isolation may emerge in their interactions because of experienced ethnic differences and language barriers.

In this sense, to expand the range of positive social relations in dependent old age, social policies should also consider the ethnicity of their customers and the differences between the services providing LTC. Studies have shown that mainstream care facilities can increase social isolation among older migrants because of their low level of language proficiency, which is an even greater challenge in a multilingual context such as Luxembourg. Compared to residents in ethnospecific care facilities (which pay particular attention to cultural aspects such as religion, language, and food), those attending mainstream institutions are less likely to be involved in verbal communication with other residents (Runci et al., 2014) and report low satisfaction (Runci, Redman, \& O'Conner, 2005). Thus, mainstream services alone seem unable to meet the needs and the diversity of older migrants. However, it should be not a question of either/or, but rather "how the various different models can best complement each other" (Radermacher et al., 2008, p. 18).

Future research should analyze social interactions in LTC facilities by developing ethnographic investigations inside the care homes (e.g., Hubbard et al., 2003) and daycare centers in order to learn more about older migrants' social interactions from an intersectional perspective, accounting for different axes of social differences such as gender, ethnic background, or different aspects of social class. It should also consider regional characteristics, such as the location of the care institutions and the composition and distribution of the migrant population in the territory. Moreover, the situation of mobile-care services should be more deeply investigated to further develop the opportunities of social interactions of older people living alone, taking into consideration the ethnic background from an inter- actional perspective. This is a very relevant topic in countries such as Luxembourg where the LTC policy encourages dependent people to stay at home as long as possible, and the number of people living alone increases with age, especially among women (Ferring et al., 2013). However, further studies investigating social relationships and interactions in the LTC system should also include a higher proportion of aging male immigrants to better understand the gender dimension.

\section{Acknowledgments}

This research was supported by grants from the University of Luxembourg.

\section{Declaration of Conflicts of Interest}

The authors declare that no conflicts of interest exist.

\section{References}

Ajrouch, K. J., Antonucci, T. C., \& Janevic, M. R. (2001). Social networks among blacks and whites: The interaction between race and age. Journal of Gerontology, 56B, 112-118. doi 10.1093/geronb/56.2.S112

Antonucci, T. C., \& Akiyama, H. (2002). Aging and close relationships over the life course. International Society for the Study of Behavioral Development, 1(41), 2-6. Retrieved from http://www.issbd.org/resources/files/newsletter_0102.pdf

Antonucci, T. C., Ajrouch, K. J., \& Birditt, K. S. (2013). The convey model: Explaining social relations from a multidisciplinary perspective. The Gerontologist, 54(1), 82-92. doi 10.1093/geront/gnt118

Antonucci, T.C., Birditt, K. S., \& Webster, N.J. (2010). Social relations and mortality: A more nuanced approach. Journal of Health Psychology, 15, 649-659. doi 10.1177/1359105310368189

Antonucci, T.C., Okorodudu, C., \& Akiyama, H. (2002). Well-being among older adults on different continents. Journal of Social Issues, 58, 617-626. doi 10.1111/1540-4560.00280

Baldock, C. V. (2003). Long-distance migrants and family support: A Dutch case study. Health Sociology Review, 12(1), 45-54. doi 10.5172/hesr.12.1.45

Bear, M. (1990). Social network characteristics and the duration of primary relationships after entry into long-term care. Journal of Gerontology, 45, S156-S162. doi 10.1093/geronj/45.4.S156

Brissette, I., Cohen, S., \& Seeman, T. E. (2002). Measuring social integration and social networks. In S. Cohen, L. G. Underwood, \& B. H. Gottlieb (Eds.), Social support measurement and intervention: A guide for health and social scientists (pp. 53-85). Oxford, UK: Oxford University Press.

Charmaz, K. (2006). Constructing grounded theory: A practical guide through qualitative analysis. London, UK: Sage.

Dickes, P., \& Berzosa, G. (2010). Les compétences linguistiques auto-attribuées [Self-assigned language skills]. Cahier 2010-19, CEPS/INSTEAD. Retrieved from http://www.statistiques.public.lu/catalog-publications/cahiers-CEPS/2010/19-competen ces-linguistiques.pdf 
Fernández-Ballesteros, R. (2002). Social support and quality of life among older people in Spain. Journal of Social Issues, 58, 645-659. doi 10.1111/1540-4560.00282

Ferring, D., \& Weber, G. (2005). EUROFAMCARE - National background report for Luxembourg. Hamburg: European Union. Retrieved from http://www.uke.de/extern/eurofamcare/documents/nabares/nabare_luxembourg_rc1_a4.pdf

Ferring, D., Heinz, A., Peltier, F., \& Thill, G. (2013). Les personnes âgées [The elderly people]. In STATEC: Recensement de la Population 2011, Premiers résultats, 29. Retrieved from http://www.statistiques.public.lu/catalog-publications/RP20 11-premiers-resultats/2013/29-13-FR.pdf

Fredrickson, B. L., \& Carstensen, L. L. (1990). Choosing social partners: How old age and anticipated endings make people more selective. Psychology and Aging, 5, 335-347. Retrieved from http://www.ncbi.nlm.nih.gov/pmc/articles/PMC3155996/

Fuller-Iglesias, H. R., Webster, N., \&Antonucci, T. C. (2013). Adultfamily relationships in the context of friendship. Research in Human Development, 10, 184-203. doi 10.1080/15427609.2013.786562

Hartmann-Hirsch, C. (2011). Luxembourg's corporatist Scandinavian welfare system and incorporation of migrants (CEPS-INSTEAD Working Paper 29). Retrieved from http://www.statistiques.public.lu/catalog-publications/working-papers-CEPS/ 2011/29-2011.pdf

Hollstein, B. (2002). Soziale Netzwerke nach der Verwitwung. Eine Rekonstruktion der Veränderungen informeller Beziehungen [Social networks after widowhood. A reconstruction of the changes of informal relationships]. Opladen: Leske + Budrich.

Hubbard, G., Tester, S., \& Downs, M. G. (2003). Meaningful social interactions between older people in institutional care settings. Ageing and Society, 23, 99-114. doi 10.1017/S0144686X02008991

IGSS (Inspection générale de la sécurité sociale). (2014). Rapport Général sur la Sécurité Sociale au Grand-Duché de Luxembourg 2013 [General report on the social security in the Grand Duchy of Luxembourg 2013]. Luxembourg: Ministère de la Sécurité Sociale. Retrieved from http://www.mss.public.lu/publications/rapport_general/rg2013/rg_2013.pdf

Jenkins, R. (1997). Rethinking ethnicity: Arguments and explorations. London, UK: Sage.

Kahn, R. L., \& Antonucci T. C. (1980). Convoys over the life course: Attachment, roles, and social support. In P. B. Baltes \& O. Brim (Eds.), Lifespan development and behavior (Vol. 3, pp. 254-283). New York: Academic Press.

Koch, A., \& Weisgerber, C. (2011, October). Facts about elderly people and long-term care in Luxembourg. Paper presented at the Closing the Gap - In Search for Ways to Deal with Expanding Care Needs and Limited Resources, Stockholm, Sweden.

Lee, D.T.F., Woo, J., \& Mackenzie, A. E. (2002). A review of older people's experiences with residential care placement. Integrative literature reviews and meta-analyses. Journal of Advanced Nursing, 37(1), 19-27. doi 10.1046/j.1365-2648.2002.02060.x

Makoni, S., \& Grainger, K. (2002). Comparative gerontolinguistics: Characterizing discourses in caring institutions in South Africa and the United Kingdom. Journal of Social Issues, 58, 805-824. doi 10.1111/1540-4560.00291

Ministry of Social Security (2015). L'assurance dépendance-guide pratique [Care insurance - Practical guide]. Luxembourg. Retrieved from http://www.mss.public.lu/publications/dependence/ad_guide_pratique_fr.pdf

Radermacher, H., Feldman, S., \& Browning, C. (2008). Review of lit- erature concerning the delivery of community aged care services to ethnic groups. Melbourne, Australia: Ethnic Communities Council of Victoria and Monash University.

Runci, S. J., Eppingstall, B. J., Van der Ploeg, E. S., \& O’Conner, D. W. (2014). Comparison of family satisfaction in Australian ethnospecific and mainstream aged care facilities. Journal of Gerontological Nursing, 40(4), 54-63. doi 10.3928/0098913420131219-01

Runci, S. J., Redman, J. R., \& O'Conner, D. W. (2005). Language use of older Italian-background persons with dementia in mainstream and ethnospecific residential care. International Psychogeriatrics, 17, 699-708. doi 10.1017/S1041610205002309

Stoller, E. P., \& Perzynski, A. T. (2003). The impact of ethnic involvement and migration patterns on long-term care plans among retired Sunbelt migrants: Plans for nursing home placement. Journal of Gerontology: Social Sciences, 58B, S369-S376. Retrieved from http://psychogerontology.oxfordjournals.org/content/58/6/S369.long

Torres, S. (2015). Expanding the gerontological imagination on ethnicity: Conceptual and theoretical perspectives. Ageing and Society, 35, 935-960. doi 10.1017/S0144686X14001330

Torres, S., \& Karl, U. (2016). A migration lens on inquiries into aging, old age and elderly care: Carving a space while assessing the state of affairs. In U. Karl \& S. Torres (Eds.), Ageing in contexts of migration (pp. 1-12). Abingdon: Routledge.

Uchino, B. N. (2009). Understanding the links between social support and physical health. A life-span perspective with emphasis on the separability of perceived and received support. Perspectives on Psychological Science, 4, 236-255. doi 10.1111/j.17456924.2009.01122.x

Van Holten, K., \& Soom Ammann, E. (2016). Negotiating the potato: The challenge of dealing with multiple diversities in elder care. In C. Schweppe \& V. Horn (Eds.), Transnational aging: Current insights and future challenges (pp. 200-216). Abingdon: Routledge.

Van Tilburg, T., \& Van Groenou, M. B. (2002). Network and health changes among older Dutch adults. Journal of Social Issues, 58, 697-713. doi 10.1111/1540-4560.00041

Victor, C., Scambler, S., Bond, J., \& Bowling, A. (2000). Being alone in later life: Loneliness, social isolation and living alone. Reviews in Clinical Gerontology, 10, 407-417. doi 10.1017/ S0959259800104101

Wilding, R. (2006). "Virtual" intimacies? Families communicating across transnational contexts. Global Networks, 6, 125-142. doi 10.1111/j.1471-0374.2006.00137.x

Zahlen, P. (2016). Elderly migrants in Luxembourg: Diversity and inequality. In U. Karl \& S. Torres (Eds.), Ageing in contexts of migration (pp. 39-55). Abingdon: Routledge.

Manuscript received: 31.10.2015

Manuscript accepted after revision: 10.03.2016

\section{Anne Carolina Ramos}

Université du Luxembourg

Maison des Sciences Humaines

11, Porte des Sciences

4366 Esch-sur-Alzette

Luxembourg

annecarolina.ramos@uni.lu 